\title{
Analizando el marco normativo aplicable a la Consulta Previa
}

\author{
César Bazán Seminario \\ Abogado por la Pontificia Universidad Católica del Perú. \\ Máster en Estudios Latinoamericanos por la Universidad Libre de Berlín. \\ Abogado e investigador del Área Pueblos Indígenas del \\ Instituto de Defensa Legal - IDL.
}

José Antonio Honda Kurokawa

Abogado por la Pontifica Universidad Católica del Perú. Ex Miembro del Comité Legal Eléctrico de la Sociedad Nacional de Minería, Petróleo y Energía.

Francisco Tong Gonzáles

Abogado por la Universidad de Lima. Máster en Mineral Law and Policy por la Universidad de Dundee. Miembro del Consejo Directivo del Instituto de Derecho de Minería, Petróleo y Energía. Ex Miembro del Consejo Directivo de la Revista ADVOCATUS.

Ha sido profesor del curso de Derecho Minero, Petróleo y de Gas de la Universidad Peruana de Ciencias Aplicadas y en los Posgrados de la Universidad del Pacífico y de la Pontificia Universidad Católica del Perú.

Vito Verna Coronado

Abogado por la Pontificia Universidad Católica del Perú. Máster en Economía y Gestión Ambiental por la Universita Commerciale Luigui Bocconi.

Profesor de Posgrado del curso Gestión Racional de los Residuos Sólidos en la Maestría de Desarrollo Ambiental de la Pontificia Universidad Católica del Perú y del curso de pregrado Desarrollo Sostenible e Institucionalidad Ambiental de la Universidad Científica del Sur.

En junio del año 2009, ocurrió un enfrentamiento en la provincia de Bagua, Amazonas, producto del cual fallecieron 34 personas entre policías y miembros de las comunidades indígenas de la zona. El denominado "Baguazo" ocurrió como consecuencia de la omisión, por parte del Estado, de realizar la consulta previa respecto de la disposición de los suelos que eran habitados por las comunidades indígenas en Bagua y que serían utilizados para el desarrollo de proyectos de inversión

En ese sentido, surgió la necesidad de emitir una norma que permita fortalecer el derecho a la consulta previa de los pueblos indígenas. En respuesta a ello, se dispuso la dación de la Ley 29875, Ley de Consulta Previa, y el Decreto Supremo 001-2012-MC, los mismos que han suscitado múltiples observaciones y que serán motivo de análisis de la presente Mesa Redonda. 
1. En primer lugar, ¿desde cuándo se habla de "derechos de los pueblos indígenas"? ¿Desde cuándo gozan de reconocimiento?

César Bazán Seminario (CBS): Quiero empezar con un reconocimiento y agradecimiento a $\boldsymbol{A d}$ vocatus por animarse a promover un debate sobre este tema vital para el desarrollo en el Perú.

Hablar de derechos de los pueblos indígenas no es un tema reciente. Se trata de un debate muy antiguo, anterior incluso a la fundación de la República en el Perú. Un ejemplo de ello, es la reflexión sobre la condición del indio impulsado por la Escuela Salamantina y que en el Perú tuvo como actor principal a Bartolomé de las Casas. En esos tiempos coloniales en que el racismo dominaba nuestras mentes -incluso más que hoy-, la pregunta era si el indio era persona y en consecuencia si tenía derechos. Y se llegó a la conclusión de que el indio posee alma, aunque su condición diferente a la del colonizador le permite ser titular solo de ciertos derechos.

De esos tiempos a la actualidad ha corrido mucha agua bajo el puente. No creo que sea apropiado hacer un recuento histórico sobre los avances y retrocesos de las políticas y derechos respecto de los pueblos indígenas, que oscilan entre el exterminio, el asimilacionismo, el multiculturalismo y la tímida aceptación del pluriculturalismo del país.

Para este punto, creo que basta con mencionar que la Constitución de 1993, e inclusive varias de las anteriores, reconocen derechos a pueblos indígenas, como el derecho a la identidad cultural y étnica, a su propia justicia, etc. Pero, la Constitución actual no utiliza la terminología "pueblo indígena", sino comunidades campesinas y nativas y pueblo originario.

La terminología "pueblo indígena" recobra sonoridad a partir del Convenio 169 de la Organización Internacional del Trabajo, que forma parte del ordenamiento jurídico peruano desde 1995. Desde ese momento es obligatorio para el Perú el respeto del derecho que es motivo de esta entrevista: el derecho a la consulta previa, libre e informada.
Además de ese, hay otros hitos -sin contar las normas sobre comunidades campesinas y nativas o rondas campesinas, su propiedad, etc.- como las sentencias de la Corte Interamericana sobre el derecho de propiedad de pueblos indígenas y tribales, las sentencias del Tribunal Constitucional, la ley de consulta previa y ahora el reglamento.

José Antonio Honda Kurokawa (JHK): Tengo entendido que el concepto de "pueblos indígenas" como un concepto distinto al de "comunidades campesinas" o "comunidades nativas" proviene, en lo que a legislación aplicable en el Perú se refiere, del Convenio 169 de la OIT. Recordemos que la Convención 169 de la OIT fue adoptada en 1989 y fue ratificada por el Perú en 1994, entrando en vigencia para el Perú en febrero de 1995.

Antes del Convenio 169 de la OIT, nuestra legislación interna utilizaba exclusivamente los conceptos de "comunidades campesinas" y de "comunidades nativas". Me refiero a normas tan importantes como la Constitución (artículo 89) y el Código Civil (artículos 134 al 139). Existen, además, una Ley de Comunidades Campesinas y una Ley de Comunidades Nativas.

Después del Convenio 169 de la OIT, en el año 2006 se promulga una ley sobre pueblos en situación de aislamiento, que utiliza el término de "pueblos indígenas u originarios"; y el contenido de dicho término es el mismo que el recogido en el Convenio 169 de la OIT, es decir, pueblos que se autorreconocen como indígenas u originarios, que mantiene una cultura propia, así como tradiciones propias. Entonces, hoy tenemos tres conceptos:"comunidad campesina","comunidad nativa" y"pueblo indígena u originario".

Francisco Tong Gonzáles (FTG): El reconocimiento de los pueblos indígenas tiene larga data. He identificado normas desde los años 60 s que regulan la materia incluyendo, además, la Ley de Comunidades Nativas de los 70s, que luego fue derogada, pero no descarto la existencia de normas anteriores. De hecho se habla de pueblos indígenas en las Constituciones de 1933 , de 1979 y de 1993. Por lo tanto, el reconocimiento lo tienen desde hace mucho. 
Los conceptos contenidos en el Convenio 169, tampoco son nuevos. Internacionalmente, la discusión acerca de los mecanismos para protegerlos, tampoco lo es. Como ejemplo, podemos mencionar el propio Convenio 107 de la OIT de 1957 que se refiere expresamente a las poblaciones indígenas y tribales en países independientes. De hecho existen normas y tratados, entre otros documentos sobre la materia, prácticamente desde el descubrimiento de América e incluso a propósito de éste, para regular lo que ocurriría con sus habitantes y sus territorios.

Vito Verna Coronado (VVC): La Constitución de 1979 no hace alusión a la categoría "pueblos indígenas". Sin embargo, los artículos 34 y 35 se sirven de otras categorías tales como culturas nativas o comunidades quechuas, para designar a los primeros pueblos de la selva y sierra del Perú, respectivamente.

El artículo 89 de la actual Constitución hace referencia al respeto por la identidad cultural, lo que ha significado un reconocimiento mayor de los derechos de los pueblos originarios.

Corresponde decir que este artículo es un importante avance en materia constitucional; puesto que los derechos colectivos e individuales de la población indígena encuentran en el derecho a la identidad cultural un eje de referencia fundamental.

En efecto, incluso el derecho a la consulta puede concebirse como uno de naturaleza instrumental, cuyo fundamento esencial se encuentra precisamente en el derecho de estos pueblos a mantener y vivir de acuerdo con su cultural.

En el ámbito internacional, el Convenio 107 de la Organización Internacional del Trabajo (OIT) del año 1957 regía la relación Estado- Pueblos indígena bajo el paradigma de la asimilación. Esto significaba que los Estados debían procurar incorporar a la cultura mayoritaria o predominante a los grupos con culturas diferentes y minoritarias.

Sin embargo; en el año 1988, la comunidad internacional consideró conveniente replantear el paradigma de la asimilación. Es en ese contexto que en 1989 nace el Convenio 169, que plantea un nuevo paradigma: el respeto por la identidad cultural de los pueblos.

El Estado, en línea con este nuevo principio, asume la obligación de velar por la preservación de las culturas originarias y crear las condiciones adecuadas para que estas no terminen extinguiéndose.

El citado convenio internacional entró en vigencia en nuestro país en 1995, luego de su adopción en 1993. Sin embargo, hasta el día de hoy, el Estado no había hecho los esfuerzos necesarios para difundir sus alcances entre la población beneficiaria ni implementar sus estipulados. Esta larga omisión ha significado que las comunidades campesinas y nativas sean, en ocasiones, inadecuadamente informadas respecto de los alcances de los derechos que el convenio en mención les reconoce.

2. El derecho a la consulta previa se ha regulado en el Perú recientemente, mediante la Ley 29785 (en adelante, la Ley de Consulta Previa). Sin embargo, ¿era esto necesario cuando ya lo establecía y definía el Convenio 169 de la Organización Internacional del Trabajo (OIT), de obligatorio cumplimiento para nuestro Estado?

CBS: Creo que la pregunta es muy buena porque guarda un razonamiento jurídico sólido: EI Convenio 169 es de obligatorio cumplimiento para el Estado peruano y lo es desde 1995. No es necesario profundizar en que los tratados ratificados el Estado peruano deben cumplirse de buena fe, tal como lo determina la Convención de Viena; ni tampoco en que los tratados sobre derechos humanos, como el Convenio 169 , forman parte del derecho interno, tal como lo establece la cuarta disposición final y transitoria de la Constitución y el Código Procesal Constitucional. Lo mismo puede decirse de las sentencias de la Corte Interamericana de Derechos Humanos sobre pueblos indígenas - entre las que se encuentra el caso Saramaka sobre consulta- que son anteriores a la ley 29785.

El marco general es que la consulta previa a los pueblos indígenas es un derecho reconocido 
en el Perú con anterioridad a la ley 29785. Esto significa que, desde un punto de vista estrictamente jurídico, no era necesaria la ley para exigir la realización de un proceso de consulta.

Pero, contar con una ley tiene un sentido distinto. Por un lado, profundiza en ciertos aspectos del derecho a la consulta que han sido escuetamente regulados por el Convenio 169 (aunque en determinados temas la ley representa un retroceso).

Mientras que por otro lado, y esto es muy importante, la ley es un instrumento político. Es un instrumento que ha contribuido a ampliar el debate sobre lo indígena en el Perú, a visibilizar a los pueblos como actores sociales y políticos y a exigir más decididamente derechos, que a la largo de nuestra historia les han sido negados. Fíjense en esto que les digo: la ley no sólo es un instrumento jurídico, sino también un instrumento político. Al decir esto no estoy subvirtiendo el orden de las cosas. Sólo estoy constatando una realidad. Las leyes no son y nunca han sido neutrales, técnicas o asépticas. En su trasfondo, en su ADN, hay un debate y una opción política. En el caso de la ley de consulta, la opción política es la opción por el reconocimiento de derechos a sectores usualmente marginados de la sociedad peruana, que carecen de cuotas de poder a las que otros sectores sí acceden. Y ello permite alimentar un debate político (y jurídico, económico, social, etc.) en dirección hacía un país más inclusivo.

Por eso, la ley de consulta es importante. No porque reconozca un derecho: el derecho a la consulta. Ese derecho ya existía desde antes, desde 1995. Sino porque contribuye a dar la batalla política por la efectividad del derecho a la consulta y porque profundiza el debate a favor un Perú libre y moderno (o post-moderno) construido en base al respeto de los derechos de todos, donde la libertad a ser diferente está garantizada.

JHK: El Convenio de la OIT se refiere a la Consulta Previa. Pero, no a cualquier consulta la podemos calificar de Consulta Previa, propiamente dicha. Me parece que la Ley de Consulta Previa y su Reglamento son instrumentos necesarios para, considerando la realidad nacional, aplicar correctamente dicho concepto, cumpliendo el compromiso asumido con la ratificación del Convenio de la OIT. Lo importante es que hoy tenemos una Ley y un Reglamento, que regulan la implementación de la Consulta Previa y que la idea es comenzar a trabajar para que dichas normas tengan el éxito que todos esperamos, porque esto va a beneficiar no solamente a los Pueblos Indígenas sino también al Estado a quien se le otorga un rol más activo (un rol que no tenía), y a las empresas porque les va a dar mayor solidez a sus inversiones. Se trata de una norma, que bien implementada, beneficiará a toda la Sociedad.

FTG: Siendo estrictos, me parece que no era necesario pues el Convenio 169 ya era parte de nuestra legislación y había sido incorporado en nuestra normativa. Por ejemplo, es una de las fuentes que sustentan las reglas de participación ciudadana que varios sectores económicos ya han implementado en distinto grado.

Ahora bien, sobre la conveniencia de tener normas más específicas que desarrollen los conceptos del Convenio 169, quizá si era oportuno aun cuando pueda discrepar de algunos aspectos regulados en la normativa dictada. Por ejemplo, el detalle de las normas que no requieren pasar por consulta. Creo que hay otros supuestos urgentes que también merecen esa protección. Además, la falta de regulación de ciertos aspectos referidos a la impugnación de los actos procedimentales de la consulta, que el administrado no sea parte en el proceso, entre otros, que deben mejorarse.

VVC: Considero que sí fue y es necesario, por dos razones principales.

La primera tiene que ver con el valor simbólico que ostenta una ley y la necesidad del Estado peruano de dar muestras de su voluntad por reconstruir las relaciones con los pueblos originarios del Perú.

Una segunda tiene que ver con el derecho a la consulta, pieza clave del Convenio, el cual se substancia en un procedimiento de diálogo que 
debe ser promovido, organizado y concluido, por un número bastante grande de organismos públicos, desde el propio Congreso de la República hasta las municipalidades distritales.

Cualquier organismo que prepare la dación de un acto legislativo o administrativo que previsiblemente tendrá efectos directos sobre pueblos indígenas deberá someterlo, previamente, a consulta a los pueblos involucrados.

Esta multiplicidad de actores públicos requería de un estándar normativo que ordene y asegure principios base y garantías mínimas que informen cualquier proceso de consulta a realizarse en el Perú. Esta finalidad, así como la anterior trascienden a las posibilidades de un reglamento sectorial o incluso transectorial.

3. De otro lado, la tercera disposición complementaria final de la Ley de Consulta Previa, deroga el Decreto Supremo 023-2011-EM que aprueba el Reglamento del Procedimiento para la Aplicación del Derecho de la Consulta a los Pueblos Indígenas para las Actividades Minero Energéticas (en adelante, el Reglamento derogado). Al respecto, ¿era necesario derogar el referido Reglamento? ¿Qué similitudes y/o diferencias encuentra entre la Ley vigente $y$ el Reglamento derogado? ¿Era necesaria la ampliación del ámbito de aplicación de la Ley de Consulta Previa?

CBS: Para empezar daría una respuesta formal: la ley de consulta previa es posterior al reglamento de Energía y Minas, tiene mayor rango y aborda la misma materia: el derecho de la consulta a pueblos indígenas. En ese sentido, la consecuencia jurídica esperada es que el reglamento de Energía y Minas resulte derogado. Empero, lo dicho no obsta para que el reglamento derogado sea tomado en cuenta, puesto que fue una norma pionera, que recogía ciertos elementos de la consulta desarrollados en el Derecho Internacional.

Más allá de eso, puede decirse que el contexto político peruano requería señales: era necesario reemplazar el reglamento derogado por una normatividad del más alto nivel que exprese la voluntad política del Congreso y Ejecutivo por respetar derechos de pueblos indígenas.

Además, en algunos aspectos la ley de consulta fue un avance respecto del reglamento de Energía y Minas: pone en claro que el objetivo de la consulta es alcanzar el acuerdo o el consentimiento, no fija plazos extremadamente cortos que desnaturalicen el proceso de consulta, se elimina la referencia a las normas de participación ciudadana, entre otros.

Ahora bien, la ley de consulta previa es una norma general que no abarca sólo a las actividades de minería y energía reguladas por el reglamento derogado. Es una ley general que establece la obligación de consultar a los pueblos las medidas administrativas y legislativas que tengan relación directa con los derechos de los pueblos y los afecten. En concreto, la ley no restringe el derecho a la consulta sólo a actividades energéticas o mineras y es correcto que no sea así, puesto que mediante medidas de otra índole también se pueden afectar derechos indígenas.

Un ejemplo: desde el Área de Pueblos Indígenas del IDL, impulsamos un proyecto de ley de coordinación intercultural de la justicia. Lo que, básicamente, buscamos mediante este proyecto es mejorar las relaciones entre la justicia que se imparte desde el sistema estatal (jueces, fiscales, policía, etc.) y la jurisdicción de las comunidades nativas, campesinas y rondas, para que haya respeto entre ambas justicias. Para eso, el proyecto de ley regula las relaciones entre estos actores, lo que determina de alguna manera los límites de la actuación de la justicia comunal o el valor de sus decisiones frente a actores estatales. Ese proyecto de ley, que no tiene nada que ver con minería o hidrocarburos, deberá ser consultado, según mandato de la ley de consulta, ya que afecta derechos de pueblos indígenas. Así como éste hay varios ejemplos de actos administrativos y legislativos que no tienen relación directa con minería o energía y que, sin embargo, deberán ser consultados.

JHK: La respuesta es que sí era necesario derogar esa norma. Sí había diferencia. Creo que la principal diferencia es que, de acuerdo 
a ese Reglamento derogado, había que hacer consulta previa antes del otorgamiento de una concesión minera lo que sería contraproducente para los propios Pueblos Indígenas porque no sabrían sobre qué pronunciarse y contraproducente para el Estado porque no sabría sobre qué preguntar. Me explico. El término "concesión minera" es, de repente, un poco engañoso, porque la "concesión minera" no me da en sí mismo el derecho a realizar actividad minera. Por ejemplo, si alguien dice tengo una "concesión minera", un tercero, no familiarizado con la terminología legal y basada en el significado coloquial, podría entender erróneamente que el titular de una "concesión minera" puede hacer, sin mayor trámite adicional, actividad minera y la verdad es que no es así. La concesión minera es el primer paso de una cadena de pasos antes de poder hacer actividad minera. Uno primero obtiene concesión minera sin saber si en esa área de concesión va a encontrar los minerales que espera, el volumen que espera. No lo sabe. Simplemente, hace su solicitud, se le otorga su concesión y después tendrá que hacer un estudio de impacto ambiental, trabajos de exploración, un plan de minado; tendrá que obtener un acuerdo con los propietarios del terreno superficial —normalmente comunidades campesinas-, tendrá que obtener derechos de agua, etc. El punto es que si no obtiene alguno de esos requisitos adicionales no podrá realizar actividad minera por más que tenga una concesión minera. Entonces, ¿qué pasaba con el reglamento derogado? Decía que hay que hacer consulta previa antes de otorgarse la concesión y ¿sobre qué iba a consultar el Estado a los pueblos indígenas?, ¿le iba a explicar los alcances del proyecto? No, no tenía como explicarles. $\mathrm{Ni}$ la empresa ni el Estado lo pueden saber a esa altura. Me parece prudente el haber derogado ese reglamento y al contrario de aquel derogado, el nuevo es claro al establecer que la consulta debe ser antes del inicio de la actividad, así uno puede ir obteniendo todo lo necesario y antes de hacer actividad alguna se deben obtener, entre otros, los requisitos que ya he mencionado, y ahora se suma la Consulta Previa. Es decir, no se va a ver afectado al derecho colectivo del pueblo indígena a la consulta previa. Considero que ha sido prudente la derogación.
FTG: En principio estoy de acuerdo con dicha derogación y considero que era necesaria pues esta norma se dictó básicamente para cumplir con un mandato del tribunal constitucional que le ordenó al Ministerio de Energía y Minas emitir una norma regulando la materia. Sin embargo, fue preparada cuando las normas que hoy se encuentran vigentes recién se estaban gestando. Por lo tanto, era prematuro que un solo sector pretenda regular estos temas. De hecho, se incluyó en la misma un polémico listado de actividades que requerían de un proceso de consulta previa sin que, incluso, existiera una idea clara de quiénes serían objeto de la misma.

Claramente, la normativa vigente ha sido mejor preparada. Existen similitudes en los conceptos básicos y los principios generales pero le confiere un rol más activo a los distintos reguladores para que adecúen estos principios y conceptos a las situaciones particulares en las que estos actúan.

De hecho no se incluye listado alguno de actividades que requieren la consulta sino algunas pautas generales de qué tipo de decisiones la requerirían a efectos de que los sectores respectivos determinen exactamente los actos que requieren la consulta lo cual me parece acertado.

Desde mi perspectiva, me parece que la norma puede perfeccionarse, pero lo urgente es la reglamentación de cada sector.

VVC: Considero que el Reglamento derogado adolecía de un error fundamental.

El artículo 14 establecía que la concesión minera era un acto administrativo susceptible de afectar directamente a los pueblos indígenas $y$, en razón de ello, su aprobación debía ser sometido a consulta previa.

En la práctica, en el Perú la concesión minera otorga únicamente una reserva de área. Ella no autoriza en modo alguno actividad minera en la zona concesionada.

Por otro lado, debe quedar claro que al momento de obtenerse la concesión minera, por 
lo general, no existe ni en términos de prefactibilidad una idea de los alcances del futuro proyecto, por lo que un eventual proceso de consulta carecería de lo principal, vale decir, la materia objeto de consulta.

4. En relación al órgano competente, ¿considera adecuada la decisión de establecer como el órgano técnico especializado en materia indígena del Poder Ejecutivo al Viceministerio de Interculturalidad del Ministerio de Cultura? ¿El Ministerio de Ambiente y el Ministerio de Energía Minas deberían tener participación en dicho proceso?

CBS: Esta pregunta nos remite a un tema muy relevante para el Perú actualmente: la construcción de institucionalidad para la protección de derechos indígenas en el Perú.

La interculturalidad y la protección de derechos indígenas es un asunto que cruza trasversalmente a los diversos sectores en los que está dividida la Administración peruana. Anteriormente coloqué un ejemplo referido a justicia, en donde encontramos el vasto campo de la justicia intercultural. Lo mismo podría decirse de la educación, campo en el cual se ha debatido mucho acerca de una educación intercultural, que respete las diversas cosmovisiones y germine una educación enraizada en ellas.

Como puede intuirse, la cuestión indígena es un tema que va más allá del sector minero, energético o medioambiental. Muchas veces se quiere reducir lo indígena a su contencioso con las industrias extractivas, ya que en gran parte de los conflictos sociales están enfrentadas comunidades e industrias. Sin duda, los conflictos es uno de los temas primordiales y urgentes de la cuestión indígena, pero no es el único.

Para abordar la temática indígena con responsabilidad es necesaria una reforma intercultural del Estado, que contribuya a que el aparato estatal respete cosmovisiones diferentes, tenga una decidida vocación de diálogo intercultural y se tutelen los derechos de los pueblos indígenas. En esa tarea, el Viceministerio de Interculturalidad y el Ministro de Cultura deben jugar un pa- pel fundamental en coordinación con todos los otros sectores. Justamente una de las acciones urgentes es, desde el Viceministerio, promover la construcción institucionalidad indígena estatal, para que desde el Estado se puedan dar respuestas sostenibles a los problemas de los pueblos en materia medioambiental, salud, educación, conflictos con industrias extractivas, promoción de actividades productivas, justicia, etc.

JHK: Me parece que sí deberían tener participación en la consulta. ¿Por qué? Cuando se hace una consulta, el Estado de alguna manera tiene que estar de acuerdo con el proyecto. Si no estuviera de acuerdo ni siquiera lo debería someter a consulta, el Estado debe someter a consulta aquello que le parece viable, técnica, ambiental y legalmente, sino ¿para qué lo consulta? Si el Estado está de acuerdo, debe llevar la posición de "busquemos conocer la opinión de los Pueblos Indígenas", pero partiendo de que el propio Estado sí estaría de acuerdo con el desarrollo del proyecto sino, no tendría razón la consulta. Quienes deben conocer con mayor detalle las razones por las cuales el proyecto económico es bueno, o la norma si se quiere hablar sobre una disposición de carácter general, son los Ministerios que han recibido los expedientes de aprobación del proyecto y no sólo el Ministerio de Cultura. Considero que debe haber un trabajo coordinado porque quienes conocen las razones por las cuales el proyecto económico o el borrador de norma son beneficiosos, serían los Ministerios de los sectores económicos involucrados. Entonces, trabajando de una manera coordinada pueden lograrse mejores efectos, esto podría irse mejorando ya en la aplicación de estas normas.

FTG: Considero adecuado que exista un órgano técnico especializado. Ahora bien, tengo dudas acerca de si el Ministerio de Cultura o el Ministerio del Ambiente están preparados para asumir este encargo. Quizá debiera tratarse de una entidad independiente que dependa de alguno de estos ministerios. Lo que sí me queda claro es que no debería ser el Ministerio de Energía y Minas pues se trata de un tema que involucra al Estado, a todos los sectores productivos, a la 
población y a la nación en su conjunto y que debe ser manejado técnicamente pero como un asunto que innegablemente tiene contenido político. Estoy de acuerdo y creo que es fundamental que el Ministerio de Energía y Minas intervenga, pero no que lo dirija. De hecho quizá convenga que se trate de una entidad que dependa directamente de la Presidencia del Consejo de Ministros.

VVC: Lo que confiere sentido, finalidad y razón de ser a la consulta es el derecho a la identidad cultural. Quitarle la cultura a un pueblo es quitarle un referente básico de cómo vivir. El Derecho, partiendo de esta premisa, ha decidido proteger a través de la Consulta la identidad de los pueblos originarios que habitan en el Perú antes de la aparición del Estado. En ese sentido, el Ministerio de Cultura es sin duda el sector público competente.

Por otro lado, debemos tener en cuenta un rasgo importante de los pueblos indígenas: su relación con la tierra. Durante milenios esto pueblos ancestrales han desarrollado conocimientos que les han permitido convivir armónicamente con la naturaleza, en este crucial tema los sectores Ambiente y Cultura compartes un escenario de acción muy importante.

5. Los incisos i) y j) del artículo 3 del Reglamento de la Ley de Consulta Previa, aprobado por Decreto Supremo 001-2012-MC (en adelante, el Reglamento) define a las medidas legislativas como "normas con rango de ley que puedan afectar directamente los derechos colectivos de los pueblos indígenas" y a las medidas administrativas como"normas reglamentarias de alcance general así como actos administrativos". ¿La Consulta Previa podría representar un control previo de la constitucionalidad de las normas? ¿Considera usted que la Consulta Previa, en estos casos, podría representar una medida más efectiva que el proceso de inconstitucionalidad o el proceso de acción popular?

CBS: Esta pregunta remite a la consulta de actos normativos, que es llamada consulta prelegislativa. Actualmente, la Comisión de Pueblos del
Congreso, específicamente una subcomisión liderada por una excelente congresista está haciendo grandes esfuerzos por diseñar un proceso de consulta prelegislativa que respete los estándares del derecho a la consulta a los pueblos indígenas. Y curiosamente en el debate amplio no se planteó la pertinente pregunta a la que nos invita a reflexionar Advocatus.

Dicho esto, creo que el derecho de consulta prelegislativa no podría ser equiparado con un control previo de constitucionalidad de las normas, tal como este es ejercido por cortes constitucionales de otras partes del orbe.

En primer lugar, porque la finalidad de la consulta prelegislativa es tratar de lograr el acuerdo o consentimiento de los pueblos respecto del acto normativo. No se trata de un mero análisis constitucionalidad, aunque efectivamente se busca resguardar el respeto de los derechos fundamentales, especialmente de los derechos fundamentales individuales y colectivos de los pueblos. El derecho a la consulta prelegislativa tiene que ver con que la opinión de los pueblos indígenas sea requerida, debatida y tomada en cuenta de buena fe. Y ello no se puede lograr de otra manera que mediante un diálogo intercultural entre los pueblos que serán afectados y el órgano encargado de aprobar dicha medida.

El control previo de constitucionalidad de las normas no tiene necesariamente un vínculo con el diálogo intercultural para la toma de decisiones ni tiene la necesidad de llegar a acuerdos entre las partes. En cambio, en el ejercicio del derecho a la consulta previa el diálogo intercultural es sumamente importante y su finalidad es arribar a acuerdos o lograr el consentimiento.

Esa diferencia es clave. El derecho a la consulta no puede interpretarse sólo como un control de constitucionalidad previo, tal como lo entendemos normalmente los abogados, sino como un derecho que nos abre al diálogo intercultural para la toma de decisiones públicas. Se requieren herramientas de la antropología, derecho, ciencias políticas, estudios culturales y otras disciplinas para aproximarnos al derecho a la consulta. 
A la par, existen otras diferencias. El control de constitucionalidad suele encargársele a las cortes constitucionales o a una sala especializada de la Corte Suprema, salvo excepciones. Este órgano jurisdiccional valora si la futura norma se ajusta a parámetros constitucionales o no. En el caso del derecho a la consulta prelegislativa, el órgano encargado de realizar la consulta sería el propio Congreso, mediante alguno de sus órganos internos. Y para el desarrollo de la consulta hay que convocar, desde el inicio, a integrantes de los pueblos indígenas que serán afectados por la propuesta normativa. Ellos decidirán quiénes de sus integrantes participarán del procedimiento de consulta, el procedimiento de consulta se realizará respetando las costumbres de los pueblos, en el idioma local y con traductores, el contenido del acto a consultarse será previamente difundido ante los pueblos indígenas, ellos tendrán un lapso de tiempo previo para estudiar y debatir internamente el contenido del proyecto, etc. etc.

Por estas diferencias, creo la consulta prelegislativa no puede ser equiparada a un proceso previo de constitucionalidad de las normas, puesto que tienen una finalidad y dinámica distinta, lo que se expresa en los órganos competentes y el procedimiento a utilizarse.

JHK: Creo que hay una confusión en los conceptos porque la consulta previa no tiene que ver con la legalidad de la decisión. Si el proyecto económico o la pretensión de norma fueran ilegales, no deberían siquiera presentarse a consulta. Lo que se somete a consulta es la opinión subjetiva de la comunidad indígena respecto a si se está afectando o no sus derechos colectivos. Si se sienten afectados se puede disminuir o evitar esa afectación, si sólo se puede disminuir esa afectación entonces se puede compensar y de alguna manera ellos estar de acuerdo con el proyecto económico concreto o el proyecto de norma. Si es así, perfecto. Pero, esto es distinto a opinar sobre la legalidad de la propuesta. En el caso de detectar una ilegalidad, el Pueblo Indígena debe canalizar su posición a través de una denuncia ante la autoridad correspondiente.
FTG: De ninguna manera. Para empezar se trata de un proyecto de norma con lo cual no estamos hablando de un control normativo.

Como se sabe, el control de constitucionalidad está reservado a los órganos jurisdiccionales competentes y a las autoridades administrativas a través del control difuso. Es decir que solo estas autoridades podrían determinar la constitucionalidad o no, de una norma, y si, por resultar lesiva a un derecho fundamental, debe determinarse su inaplicación.

En este caso se trata de considerar y analizar el parecer de los pueblos indígenas pero esto no podría suponer un control de constitucionalidad ni, como la norma lo indica, un derecho de veto.

No considero que la Consulta Previa pueda representar una medida más efectiva que el proceso de inconstitucionalidad o de acción popular, como indiqué precedentemente, se trata de temas distintos que, además, tienen propósitos diferentes. Me parece errado considerar el proceso de consulta como un juicio con partes enfrentadas cuando más bien debe tratarse de un dialogo para buscar consensos. Muchas personas siguen con la idea de que se trata de una suerte de arbitraje en el que el Estado deberá resolver quien tiene la razón cuando no se trata de razones o de posiciones sino más bien de lograr que un emprendimiento beneficie de la mejor manera al país, respetando la Ley y los derechos de las personas, incluidos los pueblos indígenas.

VVC: La finalidad de la consulta es llegar a un acuerdo con los pueblos indígenas, no es un mecanismo de control constitucional.

6. El inciso k) del artículo 3 del Reglamento establece una definición genérica de lo que debemos entender por pueblo indígena u originario, ¿considera que dicha regulación posibilita que se determine con exactitud cuáles son los pueblos indígenas u originarios beneficiados con la consulta? ¿La solicitud de inicio de la consulta, podría convertirse en una herramienta burocrática antes que en el ejercicio de un derecho legítimo? 
CBS: Quiero empezar diciendo que el artículo 3 del reglamento fue un alivio. Me explico. La ley de consulta previa, en su artículo 7, plantea una definición de pueblo indígena que preocupó mucho a los que conocemos el Convenio 169 y el desarrollo jurisprudencial de la Corte Interamericana.

El artículo 1 del Convenio 169 de la OIT tiene una definición de pueblo indígena, construida en el Derecho Internacional, que no fue claramente asumida por la ley. De ese modo, una interpretación literal de la ley, tal como la que se ejerce a diario en el Perú, hubiera llevado a que muchas comunidades o pueblos hayan sido excluidas del derecho a la consulta porque no cuadraban exactamente con la definición de la ley. Ese temor fue disipado por el reglamento. Este respetó la definición establecida en el artículo 1 del Convenio 169 de la OIT y la jurisprudencia de la Corte IDH.

Ahora bien, con respecto a la pregunta creo que la definición de pueblo indígena del reglamento es correcta. Se adecúa a los estándares internacionales y da elementos para identificar pueblos indígenas: criterios objetivos y subjetivos. Objetivos: descender de poblaciones que habitaban el país antes de la colonización y conservar total o parcialmente institucionales sociales, económicas, culturales y políticas. Y subjetivo: autoreconocimiento. Además, el reglamento recurre a dos ejemplos y dice que las comunidades campesinas y nativas podrán ser reconocidas como pueblos indígenas, siempre que cumplan con estos requisitos. Desde mi punto de vista, es claro que gran parte de las comunidades campesinas y nativas del Perú cuadran con la definición de pueblo indígena esbozada por el reglamento.

Por otro lado, respecto de la segunda pregunta, la identificación de los pueblos indígenas a ser afectados por la medida administrativa o legislativa es una tarea que debe hacerse detenidamente. Ese es el punto de partida para la protección del derecho fundamental a la consulta. Por ello, considero que deben tomarse todas las precauciones razonables para evitar que alguna comunidad o pueblo quede excluido de este derecho. Para eso servirá mucho la base de datos oficial de pueblos indígenas u originarios contemplada en el artículo 20 de la ley de consulta. Dicha base de datos, facilitará la identificación de los pueblos que deben consultarse y significará un ahorro de tiempo y esfuerzos al inicio del procedimiento de consulta.

JHK: El Ministerio de Cultura, particularmente el Viceministerio de Interculturalidad va a tener un trabajo importante, arduo y necesariamente meticuloso para poder identificar correctamente a los pueblos indígenas u originarios. Creo que la definición es bastante buena, se trata de aplicar en la realidad esa definición y asignarle así los derechos que establece la ley y el reglamento a estos pueblos indígenas. Lo que sí señala la norma expresamente es que una comunidad campesina o nativa no necesariamente debe ser considerada un pueblo indígena u originario. Habrán comunidades que si lo sean y comunidades que no. Ésta es justamente la labor que tiene, aplicando los conceptos establecidos en el reglamento, que realizar el Viceministerio de Interculturalidad. Dependiendo de que tan bien lo haga, se evitarán o disminuirán posibles conflictos que puedan ocurrir si es que algún pueblo se considere indígena cuando el Viceministerio de Interculturalidad puede no considerarlo. Considero que hasta que no se tenga esta formalidad no se aplicará este derecho. Ahora, el propio Pueblo Indígena puede solicitar y sustentar su inscripción.

FTG: Es cierto que la regulación es perfectible pero me parece que se han dado ciertas pautas que permiten la identificación de aquellos grupos que claramente deben considerarse como pueblos indígenas u originarios. Adicionalmente, el hecho de que se permita a la autoridad incluir dentro del concepto, analizando caso por caso, a otros grupos puede suplir cualquier deficiencia normativa aunque estamos un poco sometidos a la discreción de la autoridad. Sin embargo, me parece que no había otra alternativa.

Respecto a si la solicitud de inicio de consulta podría convertirse en una herramienta burocrática antes que el ejercicio de un derecho legítimo, es cierto y, por eso, la importancia de que cada sector cumpla con regularlo de la mejor 
manera posible. Una eventual impugnación, la falta de representatividad de las autoridades indígenas, la aún pendiente identificación de las comunidades nativas, plazos muy largos para las actuaciones del proceso, entre otras complejidades, pueden demorar significativamente diversos emprendimientos y/o normas absolutamente necesarias para el desarrollo del país.

VVC: El concepto de pueblo indígena se define por un criterio subjetivo y otro objetivo. El primero se refiere al autoreconocimiento que el pueblo realiza de sí mismo; decir por ejemplo: "Yo soy Achuar". El segundo está vinculado a aquellas tradiciones, costumbres e instituciones ancestrales que se mantengan en todo o en parte vigentes. Si concurren ambas condiciones se puede afirmar que se está ante un pueblo indígena.

Sin embargo, el problema consiste en que, en una democracia tan débil como la nuestra, grupos no indígenas que no se sienten adecuadamente representados busquen poder participar del procedimiento de consulta.

Ello sin duda, conlleva al riesgo de desnaturalizar el derecho a la consulta, tornándolo inoperante. La solución, entonces, pasa por mejorar los mecanismos de diálogo y participación democrática para que todos los ciudadanos sean escuchados y lleguen al poder por canales regulares y la consulta se aplique a quienes les corresponde como derecho, es decir, a los pueblos originarios.

7. Los artículos 9 y 15 de la Ley de Consulta Previa establecen la posibilidad de recurrir al Poder Judicial, en caso los pueblos indígenas u originarios no estén de acuerdo con la desestimación de su petitorio o con la Decisión Final. ¿Cuáles serían las consecuencias que podría traer dicha posibilidad?

CBS: En artículo 9 y el 15 de la ley se establecen dos supuestos en que los pueblos indígenas podrían acudir al Poder Judicial para impugnar una decisión que desampara sus derechos. En el primer caso, el derecho a acceder a la consulta y, en el segundo, el derecho a que se cumplan los acuerdos que fueron resultado de la consulta.
En el primer caso, el petitorio apuntaría a cuestionar la decisión del órgano técnico especializado que niega el derecho a la consulta respecto de una medida determinada. Aquí está en juego el derecho de acceso a la consulta, tal como lo reconoce el Tribunal Constitucional (Fj. 37, STC 0022-2009-PI). Si el petitorio fuera en esa línea me parece congruente inferir que la decisión jurisdiccional sería anular el acto administrativo y ordenar que el órgano se pronuncie nuevamente; o modificar la decisión administrativa y fallar sobre el fondo a favor del inicio del procedimiento de consulta. Eso dependerá de si hay problemas con la validez del acto o con la decisión y de la necesidad de tutela urgente del derecho.

En el segundo caso, lo que se busca tutelar es el respeto de los acuerdos arribados tras el procedimiento de consulta. Si mediante el diálogo intercultural, el Estado se pone de acuerdo con el pueblo indígena sobre determinado tema, ese acuerdo debe ser respetado, lo dice el artículo 15 de la ley, el artículo 4 al referirse a la buena fe, el Convenio 169, la jurisprudencia de la Corte Interamericana, los fallos del Tribunal Constitucional y la Declaración de Derechos de los Pueblos Indígenas de las Naciones Unidas. El Estado debe respetar los acuerdos a los que llegue. Por ello, el artículo 15 dice que "los acuerdos del resultado de proceso son exigibles en sede administrativa y judicial". Eso significa que en un eventual proceso judicial, el magistrado pueda ordenar el cumplimiento cabal del acuerdo y que la medida administrativa se ejecute respetando el acuerdo.

Respecto a la posibilidad de impugnación judicial hay dos temas adicionales que quiero mencionar rápidamente. Primero: muy poco se ha debatido acerca de si el proceso para cuestionar vulneraciones al derecho a la consulta sería de corte constitucional, entiéndase amparo, o contencioso administrativo. Recordemos que el derecho a la consulta es un derecho fundamental, en el que el acceso a la consulta y el cumplimiento de los acuerdos son elementos fundamentales. Para enfrentar el dilema planteado debemos preguntarnos si el contencioso administrativo es una vía igualmente satis- 
factoria que el amparo, para la protección de derechos, tal como lo determina el artículo 5.2 del Código Procesal Constitucional.

Segundo: las vulneraciones contra el derecho a la consulta a pueblos indígenas son tuteladas también por el Sistema Interamericano de Derechos Humanos. Desde el 2001, la Corte Interamericana de Derechos Humanos ha emitido sentencias en casos relacionados a pueblos indígenas. Eso signfica que si no se encuentra tutela en sede nacional por alguna vulneración al derecho a la consulta, se podría acudir al Sistema Interamericano.

JHK: Considero que aquí debería de aplicarse una interpretación restringida en el sentido de que la evaluación que hace la autoridad debiera ser una evaluación no sujeta a revisión judicial. Me explico. Pueden someterse a revisión judicial cuestionamientos a no haber seguido las etapas del proceso, a no haber cumplido con las formalidades de la ley y del reglamento, o la existencia de alguna ilegalidad en los términos planteados en una pregunta anterior, pero no la decisión subjetiva de si un proyecto va adelante a pesar de la opinión contraria del Pueblo Indígena.

FTG: Tiene que quedar muy claro que estas impugnaciones no debieran retrasar el desarrollo del país, el dictado de normas o de decisiones administrativas. La norma efectivamente señala que la impugnación no tiene efecto suspensivo pero conviene que las autoridades sectoriales regulen muy bien esta regla general.

VVC: Yo creo que es simplemente una norma declarativa. Todo acto administrativo o legislativo es susceptible de una acción judicial al margen de que la Ley de Consulta lo establezca o no.

8. En el mismo sentido, el artículo 15 de la Ley de Consulta Previa señala que "en caso de que no se alcance un acuerdo, corresponde a las entidades estatales adoptar todas las medidas que resulten necesarias para garantizar los derechos colectivos de los pueblos indígenas u originarios y los derechos a la vida, integridad y pleno desarrollo". ¿Debe desprenderse de este artículo que la Consulta Previa no es vinculante? ¿Cómo podrían establecerse las medidas necesarias para garantizar los derechos colectivos de los pueblos indígenas $\mathrm{u}$ originarios?

CBS: La consulta previa debe llevarse a cabo de buena fe y con la finalidad de arribar a acuerdos o alcanzar el consentimiento del pueblo indígena respecto de la medida a implementarse. En caso se llegue a acuerdos, estos deberán ser respetuosos, puesto que son vinculantes.

El problema está cuando, a pesar del diálogo intercultural, no se llega a un acuerdo. En este supuesto, el órgano responsable de la consulta no puede actuar como si no hubiese habido un diálogo intercultural y los pueblos no hubiesen expresado sus opiniones y divergencias respecto del proyecto. Debe tratar de incorporar dichas opiniones en la medida administrativa o legislativa que busca actuar.

Por otra parte, debe entenderse que la ausencia de acuerdos no es un cheque en blanco para vulnerar derechos indígenas. Estos derechos están garantizados tanto por la constitución como por normas supranacionales que deben ser respetadas. Esto significa que, a pesar de no haber llegado a acuerdos, los derechos de los pueblos indígenas deben ser respetados: el derecho a la tierra, a la subsistencia, identidad, repartición de beneficios, etc. Nótese que el listado que plantea el artículo 15 es amplio, ya que se refiere al respeto a los derechos de los pueblos indígenas y los derechos a la vida, la integridad y el pleno desarrollo. En el primer grupo se consideran todos los desarrollados por el Convenio 169 y otros.

Entonces, en caso de vulneración de derechos de los pueblos indígenas puede exigirse la tutela de estos derechos ante los órganos administrativos y jurisdiccionales respectivos y por los mecanismos administrativos, penales, civiles, constitucionales, etc. que correspondan.

JHK: A partir de los problemas que surgieron en relación con Bagua hace algunos años, se emitieron dos resoluciones por el Tribunal Constitucional. En ambas resoluciones se es- 
tablecen expresamente que cuando se hace una consulta previa, los pueblos indígenas no tienen derecho de veto. Lo que dicen además, y resaltan con bastante pertinencia, es que la consulta previa es un espacio de dialogo, una oportunidad para intercambiar puntos de vista distintos provenientes de culturas distintas. Eso es lo que busca la consulta previa. Cuando nosotros tenemos una decisión final en contra de la opinión del pueblo indígena, efectivamente no es vinculante, no tienen derecho de veto, pero hay una excepción: sí hay veto si la decisión implica el traslado de este pueblo de un punto territorial a otro. Por otro lado, efectivamente, la norma precisa "hay que velar por que no se vulneren los derechos colectivos de los pueblos indígenas" y que se deberán tomar las medidas necesarias. ¿Qué medidas necesarias? En cada caso concreto deberá analizarse, por ejemplo, inspecciones permanentes de parte de la entidad supervisora haciendo hincapié en la vigilancia de determinado derecho del pueblo indígena, la inclusión en sus estudios de impacto ambiental de actividades de mitigación de los efectos, etc. Las autoridades tendrán que velar porque en cada caso concreto se establezcan de una manera eficiente dichas medidas. Si no, perderán credibilidad.

FTG: La consulta es vinculante solo respecto de los acuerdos logrados sin que exista un derecho de veto. Así lo ha establecido la norma, de manera correcta en mi opinión, al menos en ese extremo.

El hecho que se establezca que "las entidades estatales (deben) adoptar todas las medidas que resulten necesarias para garantizar los derechos colectivos de los pueblos indígenas u originarios y los derechos a la vida, integridad y pleno desarrollo" podría resultar hasta innecesario pues ciertamente las autoridades tienen dicho deber. La sutileza radica en que esto debe efectuarse en el marco de la Ley y compatibilizando los derechos de unos con los derechos de los demás.

Sobre las medidas necesarias para garantizar los derecho colectivos de los pueblos indígenas u originarios, esto se puede llevar a cabo de maneras distintas pero dependerá de cada caso determinar cuál es la mejor manera de efectuarlo. En algunos casos podrían ser medidas muy sencillas como, por ejemplo utilizando monitoreos participativos o canales de diálogo efectivos y eficientes.

VVC: El acuerdo es la finalidad de la consulta, sin embargo, es posible que este no se alcance, en este caso el Estado tiene la obligación de emitir un acto en respeto de la Constitución y la ley.

Imaginemos que se somete a consulta la certificación ambiental de un proyecto y no se logra alcanzar un acuerdo con la representación indígena. En este caso, si el Estado decide aprobarlo, debe velar por no afectar negativamente los derechos individuales y colectivos de los pueblos indígenas.

9. En relación con la oportunidad de la aplicación de la consulta previa a lo largo del ciclo de un proyecto de inversión. Para el analista económico Witson Peña, señala que "para evitar convertirse en un costo económico prohibitivo, la consulta previa tendría que aplicarse inmediatamente antes de la etapa de explotación de los recursos naturales. Si se realiza en etapas anteriores como la exploración, esto podría generar una situación altamente limitante o convertirse en una barrera a la inversión de riesgo en la etapa de exploración". Para usted, ¿en qué etapa debería aplicarse la consulta previa, para evitar mayores costos?

CBS: En lugar de enfocar el tema desde los costos, quisiera plantearlo desde la perspectiva de una mayor protección de los derechos, en este caso de los derechos de los pueblos indígenas.

Con ese sustrato, y teniendo en cuenta que la consulta se debe realizar cuando hay una afectación a los pueblos indígenas, diría que el primer momento en que puede producirse dicha afectación es en la concesión, que es uno de los momentos iniciales del ciclo de un proyecto de inversión. Si bien con posterioridad a la concesión es necesario realizar otros actos para entrar en la fase de exploración y explotación, no es necesariamente cierto que recién en la exploración y explotación se afecten derechos, 
sino que estos se pueden verse lesionados con anterioridad.

Esta postura fue asumida anteriormente por el Decreto Supremo 023-2011-EM, que es el reglamento de consulta en el sector minero y energético, derogado por la ley de consulta. Y también, es respaldada por la Corte Interamericana de Derechos Humanos en el caso Saramaka versus Surinam. La sentencia de fondo ordenó al Estado en su párrafo 194 a) revisar las concesiones otorgadas dentro del territorio Saramaka.

JHK: Antes del inicio de una actividad que pueda generar un impacto en el pueblo indígena, por ejemplo, hay exploración y explotación. A un nivel conceptual, en el sector minero hay una línea que nos traza el reglamento para hacer (i) un DIA que es un estudio ambiental menos exhaustivo, (ii) un ElAsd (estudio de impacto ambiental semidetallado) que es otro instrumento ambiental, pero cuando la actividad tiene un impacto moderado y (iii) un EIA (estudio de impacto ambiental) que es cuando la actividad va a representar un impacto ambiental importante. Entonces, cuando hablamos de exploración tenemos dos alternativas (i) DIA ó (ii) EIAsd. La norma traza una diferencia porque establece cuándo aplico un DIA o un EIAsd, y dice por ejemplo, cuando el área de exploración es menor de 10 hectáreas hago un DIA, si es mayor hago un ElAsd; cuando voy a hacer túneles y si son mayores a 50 metros hago un ElAsd y si es menor hago un DIA; para tomar muestras de la propia tierra tengo que realizar perforaciones, si las mismas exceden de 20 hago un EIAsd, cuando no hago un DIA. Considero que debemos hacer una diferencia y establecer cuándo debo hacer consulta previa porque voy a hacer una disturbación que puede afectar los derechos colectivos de los pueblos indígenas. Y que existe otro nivel en el que se puede realizar alguna actividad sin causar ningún perjuicio, para lo que sólo debe existir una conversación anticipada. Mi idea es que debe hacerse una consulta previa antes de que se realice una actividad que tenga la potencialidad de disturbar los derechos colectivos de los pueblos indígenas u originarios, por ejemplo, si mi labor de exploración va a consistir en una actividad importante, es prudente que corresponda hacer una consulta previa.

FTG: En mi opinión, la consulta previa debería incluirse como parte de los procesos de participación ciudadana ya regulados para una serie de actividades económicas. No todas las actividades generan el mismo impacto, por ende, habrá que regular cada supuesto de la mejor manera posible. Coincido en que, como se encuentra establecida y como indica el señor Peña, la consulta previa podría convertirse en un freno para el desarrollo. De hecho hay muchas actividades que se realizan en la etapa de exploración que ni siquiera implican poner un pie en el terreno. En esa línea, será mejor tener una idea más exacta de lo que se pretende hacer para luego realizar un proceso de consulta que resulte más productivo. Esto tiene, además, el beneficio de no generar expectativas innecesarias e incluso reducir los conflictos o inconvenientes.

VVC: El Perú se encuentra inmerso en un mercado global y por ello existen términos de transacción que debemos mantener competitivos. A estas alturas, eso lo debemos tener claro. Sin embargo, también es cierto que como país hemos asumido internacionalmente el compromiso de consultar previamente.

Ahora, la cuestión radica en cuando efectuar la consulta. El inciso a) del artículo 6 del Convenio 169 señala que la consulta será previa a un acto administrativo o legislativo que afecte de manera directa a los pueblos indígenas. Entonces, cabe preguntarse con toda razón si una exploración petrolera en territorio indígena afecta realmente a los indígenas. Si el acto administrativo que aprueba la exploración tiene tal significación entonces sí se les debe consultar.

Por otro lado, debemos de tener presente las posibles consecuencias sociales y judiciales de omitir la consulta, en un escenario como el peruano donde los pueblos indígenas son plenamente conscientes de su derecho a ser consultados. 